Article

\title{
Development of Sensitive and Reliable UPLC-MS/MS Methods for Food Analysis of Emerging Mycotoxins in China Total Diet Study
}

\author{
Danlei Sun, Nannan Qiu, Shuang Zhou*, Bing Lyu, Shuo Zhang, Jingguang Li, Yunfeng Zhao \\ and Yongning $\mathrm{Wu}$ *
}

China National Center for Food Safety Risk Assessment, Key Laboratory of Food Safety Risk Assessment, National Health Commission, Beijing 100021, China; sundl603@gmail.com (D.S.); qiunannan@cfsa.net.cn (N.Q.); lvbing@cfsa.net.cn (B.L.); zhangsh@cfsa.net.cn (S.Z.); lijg@cfsa.net.cn (J.L.); zhaoyf@cfsa.net.cn (Y.Z.)

* Correspondence: szhoupku@gmail.com (S.Z.); wuyongning@cfsa.net.cn (Y.W.);

Tel.: +86-10-6777-9768 (S.Z.); +86-10-5216-5589 (Y.W.)

Received: 2 February 2019; Accepted: 13 March 2019; Published: 17 March 2019

check for updates

\begin{abstract}
With the climatic changes that have taken place during the last decade, the spectrum of fungal pathogens as well as mycotoxins has considerably changed. As a result, some emerging mycotoxins have been shown to occur frequently in agricultural products. In this study, a sensitive and reliable method for the determination of 10 emerging mycotoxins (beauvericin, enniatin $A$, enniatin A1, enniatin B, enniatin B1, alternariol, alternariol monomethyl ether, altenuene, tentoxin, and tenuazonic acid) in 12 different food matrices (cereals, legumes, potatoes, meats, eggs, aquatic foods, dairy products, vegetables, fruits, sugars, beverages, and alcohol beverages) was developed and validated. After a simple extraction, a one-step sample clean-up by a HLB solid phase extraction (SPE) column was sufficient for all 12 food matrices prior to analysis with ultra-high performance liquid chromatography coupled to tandem mass spectrometry (UPLC-MS/MS). Isotope internal standards ${ }^{13} \mathrm{C}-\mathrm{TeA}, \mathrm{TEN}-\mathrm{d}_{3}$, and ${ }^{13} \mathrm{C}$-AFB2 were used for accurate quantification. Validation in terms of linearity, selectivity, sensitivity, accuracy, and precision (intra and inter-day variability) were evaluated for the 10 mycotoxins in all selected matrices. The sensitivity varied from 0.0004 to $0.3 \mathrm{ng}$ $\mathrm{mL}^{-1}$ (limits of detection) and from 0.002 to $0.9 \mathrm{ng} \mathrm{mL}^{-1}$ (limits of quantitation). The recoveries of 10 mycotoxins in fortified samples were from $60.6 \%$ to $164 \%$ including very low spiking levels in all 12 food matrices, with relative standard deviations (RSDs) less than $12 \%$. The proposed methodology was applied to the analysis of 60 samples collected from five provinces within the $6^{\text {th }}$ China Total Diet Study with the results discussed in detail. The advantages of sensitivity, accuracy, and robustness made it a powerful tool for emerging mycotoxin monitoring and dietary exposure assessment.
\end{abstract}

Keywords: emerging mycotoxins; complex food matrices; UPLC-MS/MS; total diet study

Key Contribution: An accurate and reliable UPLC-MS/MS method was developed and validated for the simultaneous quantification of 10 emerging mycotoxins (TeA; ALT; AME; AOH; TEN; BEA; ENNA; ENNA1; ENNB; and ENNB1) in 12 different food matrices; allowing these emerging mycotoxins to be included in a total diet study for the first time.

\section{Introduction}

Fungi of the genus Alternaria are ubiquitous saprophytes distributed in soil, household dirt, and decaying organic material and can cause the spoilage of fruits and vegetables during transport and storage [1]. It commonly occurs worldwide and infects various cereal crops, oilseeds, fruits, and vegetables such as wheat, sorghum, barley, apples, citrus fruits, tomato, and carrots [2-9]. 
Alternaria species produce several toxic secondary metabolites called alternaria mycotoxins (ATs), which include tenuazonic acid (TeA), alternariol (AOH), altenuene (ALT), alternariol monomethyl ether (AME), and tentoxin (TEN) [2]. Tenuazonic acid (TeA) has acute toxic effects on various mammals reviewed by Ostry [10] and Gruber-Dorninger et al. [11]. Although most alternaria toxins exhibit only low acute toxicity, there is strong evidence that $\mathrm{AOH}$ and AME are mutagenic, cytotoxic, genotoxic, and play an important role in the etiology of human esophageal cancer [12-15]. In this regard, the European Food Safety Authority (EFSA) set the tolerable daily intakes (TDI) at $2.5 \mathrm{ng} / \mathrm{kg}$ body weight per day for $\mathrm{AOH}$ and AME and $1500 \mathrm{ng} / \mathrm{kg}$ body weight per day for TeA and TEN [16,17]. Based on these thresholds, the maximum levels allowed for these toxins in food might be released by some organization and regulated in the future.

Enniatins (ENNs) and beauvericin (BEA) are a group of cyclic hexadepsipeptides consisting of alternating hydroxy acid and N-methylamino acid residues that have been discovered as early as 1947 in a strain of Fusarium oxysporum, known as emerging Fusarium mycotoxins [18]. BEA has phenyl substituents on the N-methylamino acid residue whereas ENNs have various aliphatic substituents at the same positions. They are secondary fungal metabolites produced by several Fusarium such as Beauveria, Paecilomyces, Polyporusm, and Verticillium, which are parasitic to maize, wheat, rice, and other cereals [19-22]. High levels of BEA in wheat samples reaching $4 \mathrm{mg} / \mathrm{kg}$ were reported in the Mediterranean area in a recent study [23]. BEA and ENNs share similar chemical structures and thus have similar toxic mechanisms of action including interference with the electrochemical gradient of the cell membranes by disturbing the normal physiological level of cations [24,25]. BEA can also induce apoptosis and DNA fragmentation [26], and has been proved to have genotoxicity [27,28].

A variety of the methods used in the analysis of emerging mycotoxins such as TLC, HPLC-UV, and HPLC-FLD are vulnerable to interference from co-eluting compounds and have difficulties in dealing with multiple analytes, especially if complicated food matrices are analyzed [29-33]. Recently, LC-MS/MS was used for the accurate determination of emerging mycotoxins in food matrices and has increasingly become the preferred technique due to its high selectivity and sensitivity for multi-mycotoxins analysis [34-42]. These methods started by targeting only a few toxins in limited food categories such as enniatins and beauvericin in maize [34] and eggs [35], $\mathrm{AOH}$ and AME in cereal, fruit, and vegetable products [38], and six Alternaria toxins in tomatoes [39]. Then, modified forms (mainly glucosides and sulfates) were taken into consideration and more food matrices were investigated [40-42]. The complexity of food matrices presented a big challenge to the sample preparation, HPLC separation, and matrix effect of mass spectrometry, especially when lacking the corresponding isotope-labeled internal standards. Usually, a solid phase extraction or QuEChERS purification is required to reach satisfying sensitivity and accuracy. Until now, the most frequently tested foods have been cereals, tomato-based products, eggs, fruit juices, wine, maize, and sunflower seeds [43].

Total diet study (TDS) is considered as the most efficient and effective method to provide reliable estimates of the dietary intakes of certain chemical substances for general populations recommended by the World Health Organization (WHO) [44]. China has successfully conducted five total diet studies. The strategy of the $6^{\text {th }}$ China TDS followed a similar procedure as the previous ones including dietary survey, food aggregation, collection of individual samples, cooking and preparation of food composite samples, experimental analysis of food samples, and dietary exposure assessment. The geographical areas involved in this new round of the TDS were further enlarged from 20 to 24 provinces (municipalities, autonomous regions) that represented the dietary habits in various regions of China and covered more than two-thirds of the total Chinese population. The per capita consumption of foods was classified into 13 categories according to the food composite approach adopted in this study including cereals and cereal products, legumes and related products, potatoes and potato products, meats and meat products, eggs and egg products, aquatic foods and aquatic foods products, milk and dairy products, vegetables and vegetable products, fruits and fruit products, sugar and sugar products, alcohol beverages, and condiments (including cooking oils) that were put into the other 12 
categories during cooking. Mycotoxins have been included in several previous national or regional TDSs such as the first and second French TDS [45], Spanish TDS [46], Lebanese TDS [47], Netherlands TDS [48], Hong Kong TDS, and the fourth [49] and fifth [50] China TDS (38 mycotoxins); however, none of them included emerging mycotoxins.

This study aimed to develop a method to simultaneously quantify 10 emerging mycotoxins (TeA, ALT, AME, AOH, TEN, BEA, ENNA, ENNA1, ENNB, and ENNB1) in 12 different food matrices with good accuracy and precision that was applicable for a total diet study. A sensitive and reliable UPLC-MS/MS method following an optimized solid-phase extraction (SPE) procedure was successfully developed. Ten emerging mycotoxins were completely separated under a 12-min chromatographic gradient elution. After validation, the proposed method was used to analyze 60 samples collected from five provinces within the $6^{\text {th }}$ China TDS, demonstrating the reliability and broad applicability of the proposed method. The advantages of sensitivity, accuracy, and robustness made it a powerful tool for emerging mycotoxin monitoring and dietary exposure assessment.

\section{Results and Discussion}

\subsection{Optimization of Tandem Mass Parameters}

The MS/MS conditions were optimized on a Triple Quad 6500+ mass spectrometer by the individual infusion of each compound. To obtain the most intense signals of the precursor ions, the key parameters that influence the ionization procedure such as ionization mode, ion spray voltage, declustering potential, curtain gas, source temperature, ion source gas 1 (sheath gas), and ion source gas 2 (drying gas) were manually optimized in steps. For AME and TeA, the negative mode with a spray voltage of $-4.5 \mathrm{kV}$ generated the highest precursor ions, whereas the positive mode with a spray voltage of $5.5 \mathrm{kV}$ was best for the other eight analytes. On this basis, the collision energy (CE) for each compound was tuned up individually to produce the most sensitive and stable product ions. Multi reaction monitoring (MRM) mode was used in mass detection including soft ionization, trapping precursor ions, fragmentation to product ions, and quantification. In this mode, transitions between a precursor ion and the two most abundant fragment ions were chosen for each analyte. More detailed information of the MRM parameters of the analytes are summarized in Table 1. The peak areas of quantification ions were used to estimate the concentration. The abundance of the confirmation ions relative to that of the quantification ion was used as the identification criteria. The ratio should meet the requirement of Commission Decision 2002/657/EC.

Table 1. MRM transitions of the analytes.

\begin{tabular}{|c|c|c|c|c|c|c|}
\hline Analyte & Precursor & Quantification Ion & $\mathrm{DP} / \mathrm{CE}^{1}$ & Confirmation Ion & $\mathrm{DP} / \mathrm{CE}^{1}$ & Ion Ratio \\
\hline $\mathrm{AOH}$ & 258.8 & 185.1 & $150 / 43$ & 213.0 & $150 / 37$ & 0.88 \\
\hline AME & 270.9 & 256.0 & $-110 /-29$ & 228.0 & $-110 /-39$ & 0.30 \\
\hline $\mathrm{TeA}$ & 196.2 & 139.0 & $-50 /-28$ & 112.2 & $-50 /-34$ & 0.71 \\
\hline TEN & 415.3 & 312.2 & $120 / 29$ & 301.9 & $120 / 19$ & 0.23 \\
\hline ALT & 292.9 & 275.1 & $30 / 13$ & 257.0 & $30 / 25$ & 0.70 \\
\hline BEA & 784.5 & 244.2 & $220 / 38$ & 262.3 & $220 / 34$ & 0.69 \\
\hline ENNA1 & 668.2 & 210.0 & $200 / 32$ & 228.2 & $200 / 33$ & 0.45 \\
\hline ENNA & 682.3 & 210.0 & $220 / 34$ & 228.2 & $220 / 37$ & 0.41 \\
\hline ENNB1 & 654.4 & 196.0 & $180 / 33$ & 214.1 & $180 / 35$ & 0.76 \\
\hline ENNB & 640.3 & 196.4 & $180 / 34$ & 214.2 & $180 / 33$ & 0.62 \\
\hline${ }^{13} \mathrm{C}-\mathrm{TeA}$ & 198.2 & 141.0 & $-50 /-28$ & 114.0 & $-50 /-36$ & 0.50 \\
\hline $\mathrm{d}_{2}$-TEN & 440.2 & 404.4 & $140 / 35$ & 412.4 & $140 / 37$ & 0.31 \\
\hline${ }^{13} \mathrm{C}-\mathrm{AFB} 2$ & 332.0 & 303.2 & $100 / 38$ & 273.1 & $100 / 45$ & 0.71 \\
\hline
\end{tabular}

${ }^{1} \mathrm{DP}$, declustering potential (V); CE, collision energy (eV).

\subsection{Chromatographic Separation}

The baseline-separation of the 10 target compounds have not been previously reported. The key parameters that affect chromatographic behavior were carefully investigated including column, mobile phase (organic modifier), additives (ammonium acetate, ammonium formate, ammonium bicarbonate, 
and ammonium hydroxide) at different concentrations, flow rate, gradient program, and column temperature. The separation was achieved on a CORTECS C18 UPLC column, which enabled the satisfactory resolution and sharp peaks for all of the analytes. An organic modifier (acetonitrile or methanol) in the mobile phase has a very slight influence on the chromatographic separation. Due to the clean background signal, acetonitrile was preferred as the organic modifier. Ammonium acetate, ammonium formate, and ammonium hydroxide at different concentrations were evaluated as additives and did not contribute to the intensity of ENNs and BEA, but significantly affected the ion signals of ATs (see Figure 1). It can be observed that the aqueous mobile phase containing ammonium acetate and ammonia gave rise to much better signals for all of the ATs. Particularly for TeA, $5 \mathrm{mmol} / \mathrm{L}$ ammonium acetate and $0.01 \%$ ammonia markedly enhanced the intensity more than three times higher than that of the other conditions. As a result, water with $5 \mathrm{mmol} / \mathrm{L}$ ammonium acetate and $0.01 \%$ ammonia (solvent A) and acetonitrile (solvent B) was chosen as the mobile phase for further optimization of the gradient program to achieve the satisfactory separation of all analytes. A representative chromatogram of the mixed standards of 10 emerging mycotoxins at $100 \mathrm{ng} \mathrm{mL}^{-1}$ is presented in Figure 2.

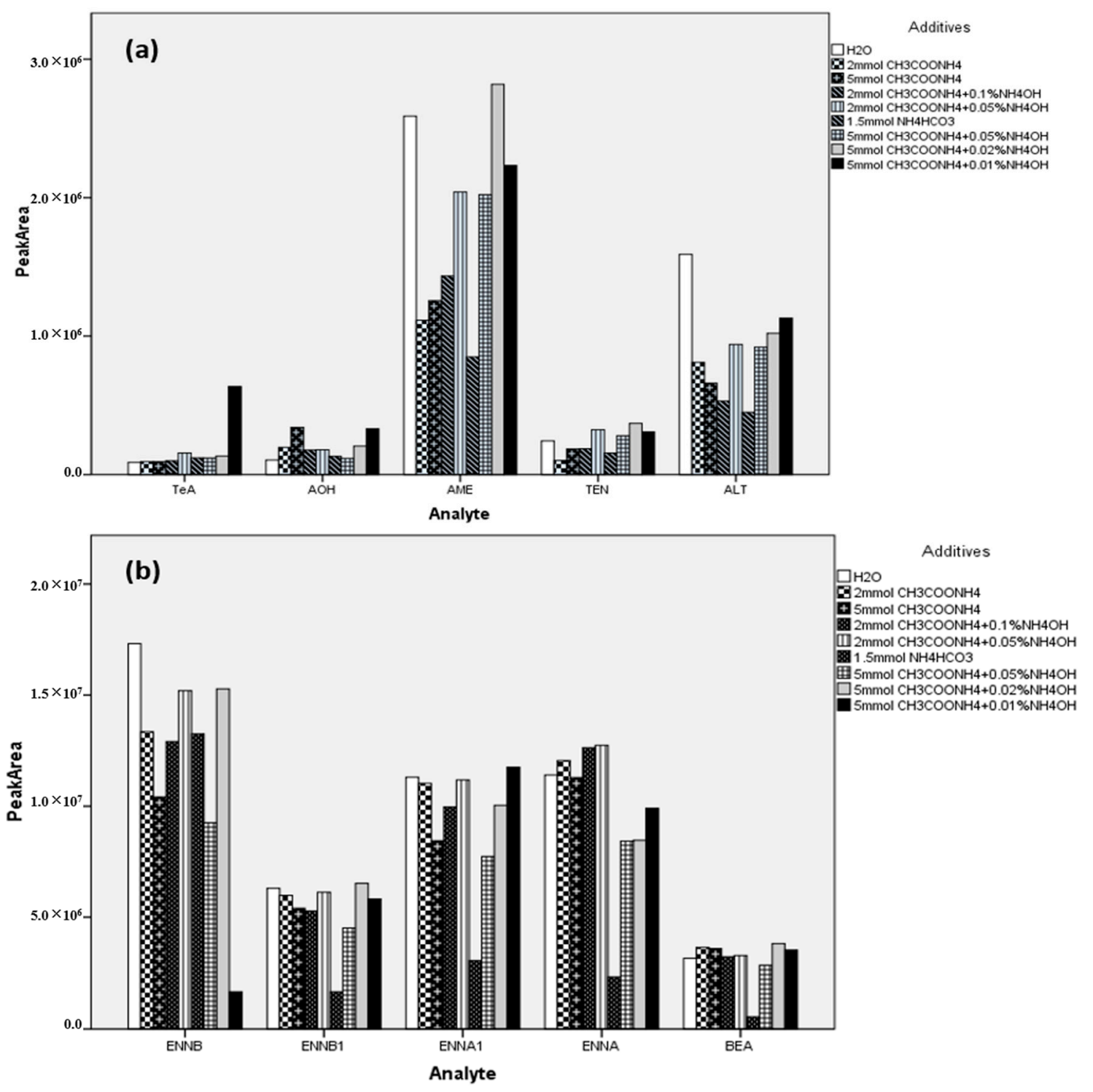

Figure 1. Effects of additives in the mobile phase on the mass signal intensities for ATs (a), ENNs and BEA (b). Abbreviations: $\mathrm{NH}_{4} \mathrm{HCO}_{3}$, ammonium bicarbonate; $\mathrm{CH}_{3} \mathrm{COONH}_{4}$, ammonium acetate; $\mathrm{NH}_{4} \mathrm{OH}$, ammonia water solution. 


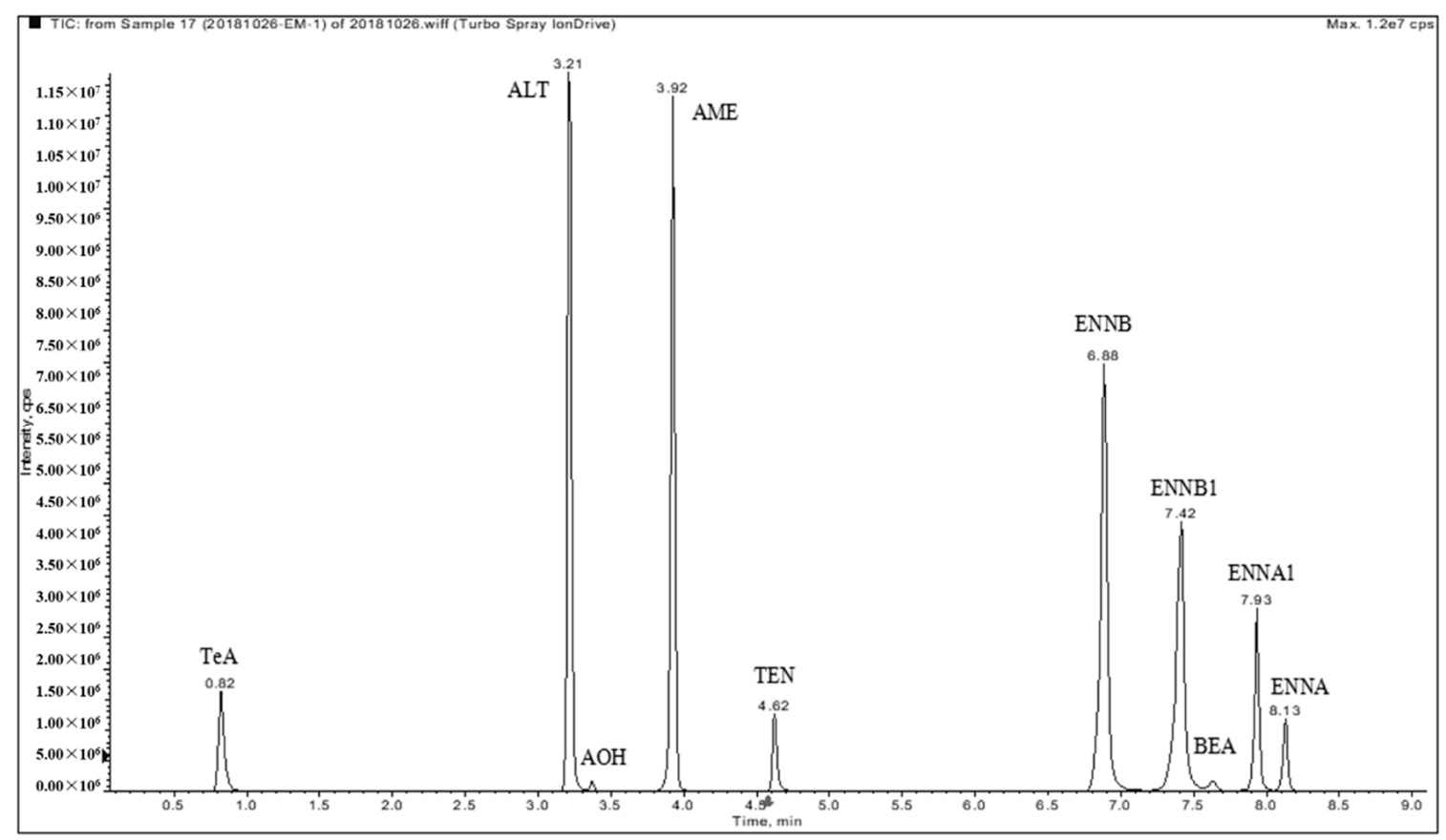

Figure 2. An overlapped chromatogram of a standard mixture of 10 emerging mycotoxins $(100 \mathrm{ng} / \mathrm{mL}$ of each) plotted by the extraction of their individual quantification ions, showing a complete UPLC separation.

\subsection{Sample Preparation}

The extraction and clean-up procedure is the most important step in multi-mycotoxin methods, especially when various different types of complex food matrices need to be analyzed for a total diet study. In previous works, several solvents have been successfully used for the extraction of emerging mycotoxins from certain food matrices [51-56]. Due to the weak acidity of TeA and AOH, a phosphate buffer $\left(0.05 \mathrm{~mol} \mathrm{~L}^{-1}, \mathrm{pH} 3.0\right)$ was used to prepare the extraction solvent to enhance the solubility of acid compounds in the acetonitrile/methanol/water (45/10/45) mixture.

Total diet samples contain diverse ingredients (fat, proteins, nutrients, carbohydrate, etc.) that may markedly influence the ionization of target compounds or increase the risk of clogging. Accordingly, a purification step that can remove most of the matrix interference and obtain a satisfying recovery of the target analytes is required. Several cartridges used in our previous works for mycotoxin extraction were evaluated including Mycosep 226, Oasis HLB, and Oasis C18 cartridges. The Mycosep 226 multifunctional cartridge is a one-step clean-up column that absorbs and removes the impurities while allowing the target analytes to pass through. This was successfully applied to the measurement of 33 mycotoxins in food samples from the $5^{\text {th }}$ China TDS [50]. Two types of conventional reverse-phase SPE cartridges, Oasis HLB and C18, are also powerful tools that have been widely used in mycotoxin analysis. Herein, the standard solution of 10 emerging mycotoxins was treated by the three cartridges to assess their recovery performance. According to the difference in adsorption theory and the manuals provided by the supplier, the three cartridges were operated following different protocols. For the HLB and C18 cartridges, a standard solution prepared in acetonitrile/water (10/90) was loaded, and $5 \mathrm{~mL}$ methanol/water solution $(\mathrm{V} / \mathrm{V}=20 / 80)$ was used to wash the cartridge followed by elution with $5 \mathrm{~mL}$ methanol and then $5 \mathrm{~mL}$ acetonitrile. The eluent was nitrogen-dried and reconstituted prior to UPLC-MS/MS analysis. For the Mycosep 226 cartridge, a standard solution prepared in acetonitrile/water (86/14) was allowed to pass through and was collected for the nitrogen-dried, reconstituted, and UPLC-MS/MS analysis. Figure 3 demonstrates the percentage recoveries obtained from the Mycosep 226, HLB, and C18 cartridges for the 10 emerging mycotoxins. The C18 cartridge presented high recoveries only for AOH, AME, ALT, and TEN. This could be because the polar compound TeA may have low adsorption on the C18 sorbent, while the ENNs and BEA might not be 
effectively eluted. For the Mycosep 266 cartridge, the recoveries of the 10 mycotoxins largely varied from $0 \%$ to nearly $100 \%$, which was attributed to the retention on the sorbent and loss in the collected portion. The best recovery performance was obtained on the Oasis HLB cartridge, achieving optimal extraction recoveries of $76 \% \sim 103 \%$ for all 10 emerging mycotoxins. Therefore, this cartridge was used in further optimization to be applicable to the 12 categories of food matrices. The final protocol was determined as stated in the Methods Section. It is noteworthy that filtration through a $0.22 \mu \mathrm{m}$ filter membrane is commonly needed to remove the insoluble substances and particles prior to sample injection. However, AME, AOH, and ENNs can partially bind to several types of filter membrane, so centrifuging the reconstitution solution at 20,000 rpm for $30 \mathrm{~min}$ before UPLC-MS/MS analysis was recommended.

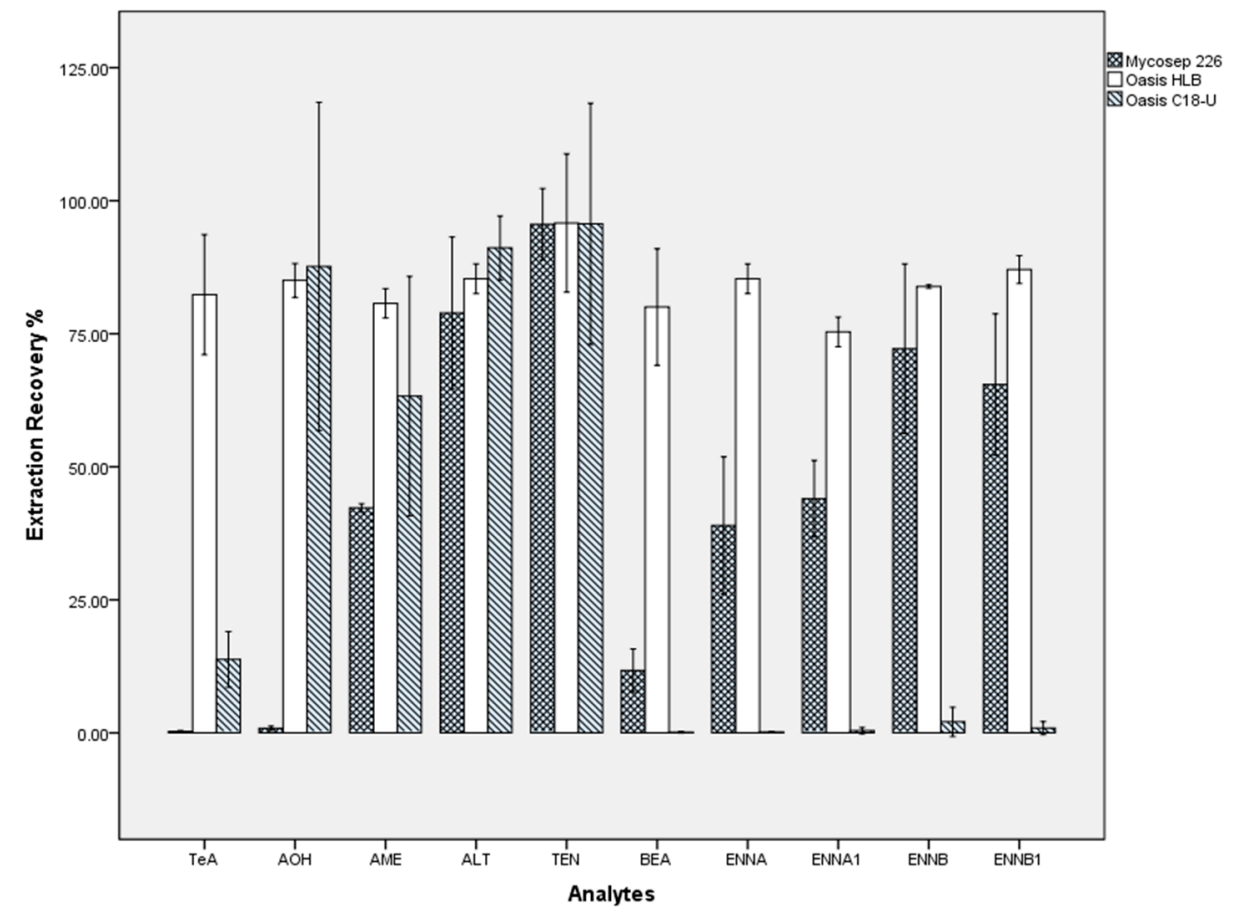

Figure 3. Recovery using two SPE cartridges and a Mycosep 226 purification cartridge for 10 emerging mycotoxins (ALT, AOH, AME, TEN, TeA, BEA, ENNA, ENNA1, ENNBm and ENNB1) spiked at $100 \mathrm{ng} \mathrm{mL}^{-1}$.

\subsection{Method Validation}

Method validation was carried out according to the guidelines established by the EC [57] and EMEA [58] in terms of the determination of linearity, selectivity, limits of detection (LODs), limits of quantification (LOQs), accuracy (recoveries), and precision (intra and inter-day variability).

The linearity was assessed from a calibration curve ranging from LOQ 500.0 $\mathrm{ng} \mathrm{mL}^{-1}$ for ATs and LOQ 50.0 $\mathrm{ng} \mathrm{mL}^{-1}$ for the ENNs and BEA on three consecutive days by using linear regression with a $1 / x$ weighting. All mycotoxins exhibited good linearity over the working range with the regression coefficient $(\mathrm{R})$ ranging from 0.989 to 0.998 and the deviations within $15 \%$ of the nominal concentrations, indicating a good linear fit for all 10 analytes.

Selectivity represented the ability of a method to differentiate the target analytes and endogenous components in the matrices. This was proved by comparing blank matrices with spiked matrices at very low concentrations for all 12 food categories. No interference signal from the endogenous matrix components at the retention time of each analyte was observed, which demonstrated the high selectivity of the method.

Sensitivities (LOD/LOQ) of the assay were obtained by analyzing spiked food matrices at low levels. $\mathrm{LOD}$ was defined at a signal to noise $(\mathrm{S} / \mathrm{N})$ ratio of $\mathrm{S} / \mathrm{N}=3$ and $\mathrm{LOQ}$ at $\mathrm{S} / \mathrm{N}=10$. For $\mathrm{LOQ}$, 
both the accuracy and precision should also be within $20 \%$. The sensitivities of each analyte were varied between the 12 food categories, which were better in a simple matrix such as cereal and beverages and lower in a matrix containing complex ingredients such as meat and meat products. AME, TEN, and BEA had similar LOQs ranging from $0.01 \mu \mathrm{g} \mathrm{kg}{ }^{-1}$ to $0.2 \mu \mathrm{g} \mathrm{kg}^{-1}$. The LOQs for TeA, $\mathrm{AOH}$, and ALT were slightly higher between $0.1-1 \mu \mathrm{g} \mathrm{kg}^{-1}$. The ENNs showed the best sensitivities with LOQs in the range of $0.001-0.05 \mu \mathrm{g} \mathrm{kg}^{-1}$. The detailed information is listed in Table 2 and Table S1, demonstrating a good sensitivity when compared to the previous methods as summarized in Table 3.

Table 2. Sensitivity, extraction recovery, and matrix effect of the method for the 12 food categories.

\begin{tabular}{|c|c|c|c|c|c|}
\hline Analyte & $\mathrm{R}_{\mathrm{E}}{ }^{1}(\%)$ & Matrix Effect (\%) & $R_{A}{ }^{2}(\%)$ & LOQ $\left(\mu \mathrm{g} \mathrm{kg}^{-1}\right)$ & LOD $\left(\mu \mathrm{gg}^{-1}\right)$ \\
\hline AME & $62.4 \sim 78.2$ & $71.4 \sim 134$ & $55.8 \sim 100.8$ & $0.01 \sim 0.08$ & $0.003 \sim 0.03$ \\
\hline $\mathrm{TeA}$ & $75.6 \sim 100.8$ & $65.6 \sim 122$ & $61.6 \sim 98.6$ & $0.1 \sim 0.9$ & $0.04 \sim 0.3$ \\
\hline TEN & $78.2 \sim 99.5$ & $99.7 \sim 162.7$ & $94.2 \sim 140.9$ & $0.05 \sim 0.2$ & $0.02 \sim 0.05$ \\
\hline ALT & 73.2 120.7 & 98.5 190.7 & $77.3 \sim 158$ & $0.2 \sim 0.9$ & $0.04 \sim 0.3$ \\
\hline $\mathrm{AOH}$ & $53.7 \sim 107.5$ & 73.9 143.5 & $51.5 \sim 111.3$ & $0.4 \sim 0.9$ & $0.1 \sim 0.3$ \\
\hline BEA & $51.3 \sim 113.3$ & $74.5 \sim 174.8$ & $53.3 \sim 152.3$ & $0.01 \sim 0.08$ & $0.002 \sim 0.02$ \\
\hline ENNA1 & $55.5 \sim 110.7$ & 71.4 188.2 & $63.8 \sim 146.6$ & $0.007 \sim 0.06$ & $0.002 \sim 0.1$ \\
\hline ENNA & $54.4 \sim 117.0$ & 72.3 155.66 & $48.4 \sim 182.1$ & $0.007 \sim 0.06$ & $0.002 \sim 0.02$ \\
\hline ENNB1 & $56 \sim 89.0$ & $114.4 \sim 196.7$ & $76.5 \sim 139$ & $0.007 \sim 0.06$ & $0.002 \sim 0.02$ \\
\hline ENNB & $54 \sim 110.7$ & $115.7 \sim 170.0$ & 74.4 135.1 & $0.002 \sim 0.04$ & $0.0004 \sim 0.01$ \\
\hline
\end{tabular}

Table 3. Analytical methods for emerging mycotoxins in food matrices and their processed products.

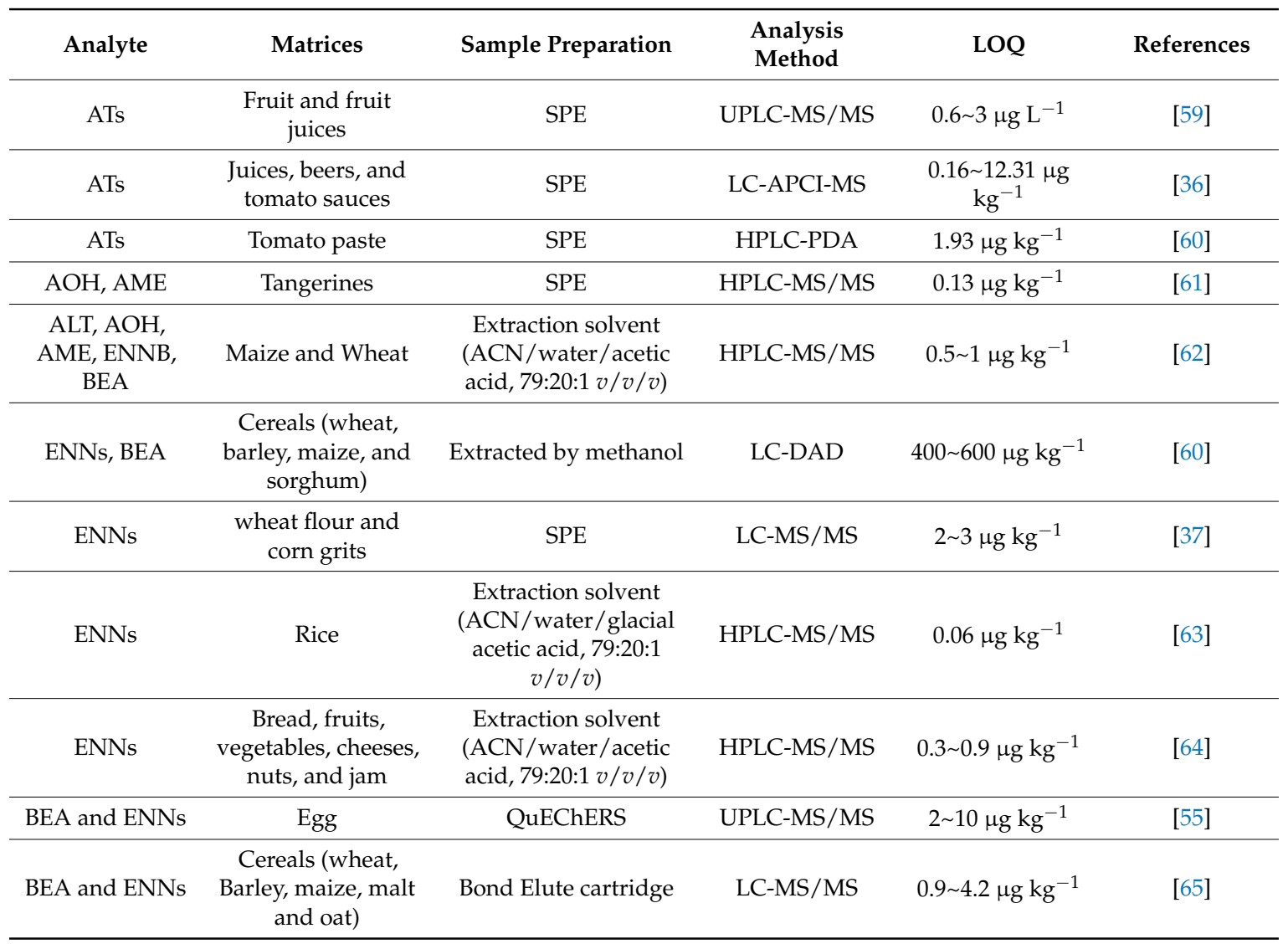

The apparent recovery $\left(R_{A}\right)$, extraction recovery $\left(R_{E}\right)$, and matrix effects $(M E)$ were also evaluated to separately evaluate the sample preparation step and instrumental detection step using the following formulas [66]:

$$
\mathrm{R}_{\mathrm{E}}(\%)=\mathrm{C} / \mathrm{B} \times 100 \%
$$




$$
\begin{aligned}
& \mathrm{ME}(\%)=\mathrm{B} / \mathrm{A} \times 100 \%, \\
& \mathrm{R}_{\mathrm{A}}(\%)=\mathrm{C} / \mathrm{A} \times 100 \%,
\end{aligned}
$$

where $\mathrm{A}$ is the average peak area of the analyte in standard solution; $\mathrm{B}$ is the average peak area of the analyte in sample matrix spiked after sample preparation; and $C$ is the average peak area of the analyte in the sample matrix spiked before sample preparation. The $R_{\mathrm{E}}$ ranged between $51.3 \% \sim 120.7 \%$ and matrix effects between $65.6 \%$ and $196.7 \%$ were obtained for all of the analytes in the 12 food categories (Table 2). The results demonstrated an effective analyte extraction, while on the other hand, stretched the need of IS compensation.

The accuracy, expressed as the method recoveries $\left(R_{M}\right)$, as well as the inter-day and intra-day precision were investigated at low, medium, and high spiking levels $\left(2,20\right.$, and $200 \mathrm{\mu g} \mathrm{kg}^{-1}$ for ATs and $0.2,2,20 \mu \mathrm{g} \mathrm{kg}^{-1}$ for ENNs and BEA) in a blank food matrix on three different days in six replicates with internal standards correction. Nearly all of the emerging toxins showed satisfying results in 12 food categories with recoveries between $70 \sim 130 \%$ and intra-day/inter-day precisions lower than $12 \%$, except for certain ENNs at a very low concentration of $0.2 \mu \mathrm{g} \mathrm{kg}^{-1}$ in cereals, potatoes, and eggs, giving slightly higher recoveries reaching $164 \%$ (Table 4 ). This can be partially attributed to the lack of a corresponding isotope labeled standard for the ENNs group. So, ${ }^{13} \mathrm{C}$-AFB1 with a similar polarity and sample preparation recovery was selected as the reference IS for the ENNs quantification.

\begin{tabular}{|c|c|c|c|c|c|}
\hline \multirow{2}{*}{ Analyte } & \multirow{2}{*}{$\begin{array}{l}\text { Spiked Level } \\
(\mathrm{ng} / \mathrm{mL})\end{array}$} & \multirow{2}{*}{$\begin{array}{l}\text { Measured Value } \\
(\mathrm{ng} / \mathrm{mL})\end{array}$} & \multirow{2}{*}{$\underset{(\%)}{R_{M}{ }^{1}}$} & \multicolumn{2}{|c|}{ RSD (\%) } \\
\hline & & & & Intra-Day & Inter-Day \\
\hline \multirow[t]{3}{*}{ AME } & 2 & $1.68(1.26 \sim 2.63)$ & $84.04(62.8 \sim 131.1)$ & $1.2 \sim 11.8$ & $3.6 \sim 12.2$ \\
\hline & 20 & 16.08 (14.36 21.86) & 80.38 (71.8 109.3) & $1.2 \sim 5.2$ & $3.6 \sim 8.7$ \\
\hline & 200 & $158.93(131.00 \sim 188)$ & $79.46(65.5 \sim 94)$ & $2.1 \sim 7.6$ & $2.8 \sim 10.3$ \\
\hline \multirow[t]{3}{*}{$\mathrm{TeA}$} & 2 & 2.07 (1.62 2.58) & $103.28(81 \sim 129.1)$ & $1.2 \sim 6.9$ & $3.3 \sim 9.3$ \\
\hline & 20 & 18.63 (17.07 20.25) & 93.18 (85.3 101.3) & $1.4 \sim 8.2$ & $3.2 \sim 10.9$ \\
\hline & 200 & $179.08(171.4 \sim 194)$ & 89.53 (85.7 97) & $0.9 \sim 7.8$ & $3.2 \sim 10.5$ \\
\hline \multirow[t]{3}{*}{ TEN } & 2 & $2.27(1.87 \sim 2.52)$ & $113.58(93.5 \sim 125.9)$ & $2.2 \sim 9.5$ & $4.4 \sim 11.8$ \\
\hline & 20 & $21.60(16.35 \sim 26.34)$ & $107.11(81.8 \sim 131.7)$ & $1.2 \sim 9.2$ & $3.2 \sim 10.8$ \\
\hline & 200 & $203.21(167.3 \sim 232.9)$ & 99.38 (75.8 116.4) & $1.6 \sim 6.3$ & $2.3 \sim 9.8$ \\
\hline \multirow[t]{3}{*}{ ALT } & 2 & $2.28(1.71 \sim 2.69)$ & $113.92(85.5 \sim 134.6)$ & $1.6 \sim 8.1$ & $3.6 \sim 10.5$ \\
\hline & 20 & 21.96 (15.98 25.42) & $109.79(80 \sim 127.1)$ & $1.2 \sim 8.4$ & $6.3 \sim 11.3$ \\
\hline & 200 & $205.13(151.5 \sim 257.2)$ & $102.58(75.8 \sim 128.6)$ & $1.6 \sim 7.8$ & $4.3 \sim 10.2$ \\
\hline \multirow[t]{3}{*}{$\mathrm{AOH}$} & 2 & $2.06(1.41 \sim 2.88)$ & 102.98 (70.7 143.8) & $2.1 \sim 8.2$ & $4.8 \sim 11.2$ \\
\hline & 20 & 17.19 (13.59 24.16) & $85.98(67.9 \sim 120.8)$ & $2.4 \sim 11.1$ & $5.1 \sim 12.3$ \\
\hline & 200 & $176.87(136.2 \sim 257.6)$ & $88.43(68.1 \sim 128.8)$ & $1.5 \sim 9.8$ & $3.2 \sim 10.2$ \\
\hline \multirow[t]{3}{*}{ BEA } & 0.2 & $0.22(0.13 \sim 0.3)$ & $110.79(63.1 \sim 149.1)$ & $1.5 \sim 9.6$ & $4.8 \sim 11.2$ \\
\hline & 2 & $1.90(1.31 \sim 2.84)$ & 94.89 (65.3 141.9) & $2.0 \sim 7.7$ & $4.1 \sim 9.6$ \\
\hline & 20 & 16.77 (12.31 24.75) & $83.88(61.5 \sim 123.8)$ & $2.1 \sim 9.1$ & $5.3 \sim 10.9$ \\
\hline \multirow[t]{3}{*}{ ENNA1 } & 0.2 & $0.23(0.13 \sim 0.31)$ & $114.33(64.5 \sim 154.3)$ & $1.2 \sim 8.1$ & $2.4 \sim 10.2$ \\
\hline & 2 & $1.78(1.21 \sim 2.57)$ & $88.83(60.6 \sim 128.5)$ & $1.3 \sim 5.6$ & $2.5 \sim 8.8$ \\
\hline & 20 & $18.12(12.22 \sim 26.81)$ & 90.62 (61.1 134.1) & $2.3 \sim 9.2$ & $4.4 \sim 11.5$ \\
\hline \multirow[t]{3}{*}{ ENNA } & 0.2 & $0.22(0.12 \sim 0.33)$ & $107.68(60.3 \sim 164.4)$ & $2.6 \sim 6.5$ & $4.8 \sim 10.1$ \\
\hline & 2 & $1.92(1.23 \sim 2.7)$ & 98.38 (61.6 145.3) & $1.3 \sim 4.8$ & $2.3 \sim 8.3$ \\
\hline & 20 & $18.75(13.96 \sim 27.64)$ & $93.73(69.8 \sim 138.1)$ & $1.2 \sim 10.1$ & $2.1 \sim 12.1$ \\
\hline \multirow[t]{3}{*}{ ENNB1 } & 0.2 & $0.21(0.15 \sim 0.31)$ & 104.08 (72.7 154.9) & $1.1 \sim 5.9$ & $3.8 \sim 10.2$ \\
\hline & 2 & $1.76(1.32 \sim 3.14)$ & $88.23(66.2 \sim 156.8)$ & $1.7 \sim 9.1$ & $3.6 \sim 10.2$ \\
\hline & 20 & $17.64(12.94 \sim 26.66)$ & $88.23(64.7 \sim 133.3)$ & $1.4 \sim 8.4$ & $4.3 \sim 11.3$ \\
\hline \multirow[t]{3}{*}{ ENNB } & 0.2 & $0.20(0.14 \sim 0.31)$ & 101.13 (71.9 153.4) & $2.4 \sim 5.6$ & $4.2 \sim 10.8$ \\
\hline & 2 & $1.81(1.32 \sim 2.53)$ & $90.26(65.9 \sim 126.5)$ & $1.3 \sim 10.3$ & $4.3 \sim 11.2$ \\
\hline & 20 & 19.31 (12.16 35.19) & 96.54 (60.8 175.9) & $1.9 \sim 9.1$ & $2.3 \sim 11.5$ \\
\hline
\end{tabular}

Table 4. Accuracy and precision of the method for the 12 food categories (mean and range).

${ }^{1} \mathrm{R}_{\mathrm{M}}$, method recovery. 
The TDS composite sample of each food category was made by blending the single samples after cooking with weights proportional to its consumption, which resulted in a more complicated matrix and a dilution of the target analytes. Therefore, high sensitivity and wide applicability are required for the analytical method used in the TDS. The validation parameters achieved in this section demonstrated a qualified method that could guarantee a reliable dietary exposure study and thereafter a risk assessment for emerging mycotoxins.

\subsection{Application of the Method in the $6^{\text {th }}$ China TDS}

The developed and validated method was used to identify the occurrence of 10 emerging mycotoxins in 60 food samples (five per each food category) within the $6^{\text {th }}$ China TDS. Due to the high sensitivity of the method, $75 \%$ of the 60 samples were positive for at least one emerging mycotoxin ranging from ppt to low ppb levels (Table 5). Additionally, all of the 12 food categories had detectable emerging mycotoxins, among which six categories (cereals and cereal products, legume and related products, potatoes and potato products, eggs and egg products, vegetables and vegetable products, and alcohol beverages) had a positive rate of $100 \%$ (detected in five out of five samples). Sugar and sugar products as well as beverages and water were rarely contaminated with these mycotoxins.

The most frequently found mycotoxins were TeA (45\%), ENNB (43.3\%), AME (36.7\%), and BEA (33.3\%) followed by TEN (28.3\%), ENNB1 (28.3\%), ALT (26.7\%), ENNA (21.7\%), and ENNA1 (13.3\%), while $\mathrm{AOH}$ was not detected in any of the samples. For alternaria mycotoxins, the concentrations ranged from $<$ LOD to a maximum value of $27.73 \mu \mathrm{g} \mathrm{kg}^{-1}$ for TeA, $27.53 \mu \mathrm{g} \mathrm{kg}{ }^{-1}$ for TEN, $10.92 \mu \mathrm{g} \mathrm{kg}^{-1}$ for AME, and $8.77 \mu \mathrm{g} \mathrm{kg}^{-1}$ for ALT, much higher than the concentrations of ENNs, which ranged from $<\mathrm{LOD}$ to $1.55 \mu \mathrm{g} \mathrm{kg}^{-1}$. It is also worth noting that the highest levels of TeA, TEN, BEA, ENNA, ENNA1, and ENNB1 were found in eggs and egg products, while cereals and cereal products contained the highest concentration of AME and ENNB. Therefore, eggs and cereals should be given more attention in future studies on emerging mycotoxin contamination and risk assessment. 
Table 5. Occurrence of emerging mycotoxins in food samples in the $6^{\text {th }}$ China total diet study.

\begin{tabular}{|c|c|c|c|c|c|c|c|c|c|c|c|}
\hline Food & & AME & TeA & TEN & $\mathrm{AOH}$ & ALT & BEA & ENNA & ENNA1 & ENNB & ENNB1 \\
\hline \multirow{3}{*}{ Cereals and cereal products } & Samples (n) & 5 & 5 & 5 & 5 & 5 & 5 & 5 & 5 & 5 & 5 \\
\hline & Positive (n) & 4 & 5 & 4 & 0 & 0 & 4 & 3 & 3 & 5 & 4 \\
\hline & Range $\left(\mu \mathrm{g} \mathrm{kg}^{-1}\right)$ & $0.14-10.92$ & $2.60-15.11$ & $0.22-2.28$ & - & - & $0.55-1.95$ & $0.12-0.83$ & $0.10-0.22$ & $0.37-1.05$ & $0.10-0.35$ \\
\hline \multirow{2}{*}{ Legume and related products } & Samples (n) & 5 & 5 & 5 & 5 & 5 & 5 & 5 & 5 & 5 & 5 \\
\hline & Range $\left(\mu \mathrm{g} \mathrm{kg}^{-1}\right)$ & 1.77 & $0.33-2.79$ & $0.10-0.28$ & - & - & $0.47-5.46$ & $1.03-1.26$ & $0.26-0.29$ & $0.16-0.37$ & 0.36 \\
\hline \multirow{3}{*}{ Potatoes and potato products } & Samples (n) & 5 & 5 & 5 & 5 & 5 & 5 & 5 & 5 & 5 & 5 \\
\hline & Positive (n) & 4 & 2 & 1 & 0 & 2 & 2 & 5 & 1 & 4 & 4 \\
\hline & Range ( $\mu \mathrm{g} \mathrm{kg}^{-1}$ ) & $0.13-2.40$ & $0.20-0.41$ & 0.96 & - & $1.08-1.72$ & $2.23-2.58$ & $0.13-1.01$ & 0.15 & $0.21-0.87$ & $0.11-0.34$ \\
\hline \multirow[t]{2}{*}{ Meats and meat products } & Positive (n) & 0 & 0 & 0 & 0 & 0 & 0 & 0 & 0 & 2 & 0 \\
\hline & Range $\left(\mu \mathrm{g} \mathrm{kg}^{-1}\right)$ & - & - & - & - & - & - & - & - & $0.13-0.24$ & - \\
\hline \multirow{3}{*}{ Eggs and egg products } & Samples (n) & 5 & 5 & 5 & 5 & 5 & 5 & 5 & 5 & 5 & 5 \\
\hline & Positive (n) & 2 & 4 & 2 & 0 & 0 & 3 & 3 & 2 & 4 & 4 \\
\hline & Range ( $\left.\mu \mathrm{g} \mathrm{kg}^{-1}\right)$ & $0.72-1.31$ & $0.26-27.73$ & $0.11-27.53$ & - & - & $1.28-6.70$ & $0.20-1.55$ & $0.30-0.51$ & $0.15-0.61$ & $0.18-0.50$ \\
\hline \multirow{3}{*}{$\begin{array}{l}\text { Aquatic foods and aquatic food } \\
\text { products }\end{array}$} & Samples (n) & 5 & 5 & 5 & 5 & 5 & 5 & 5 & 5 & 5 & 5 \\
\hline & Positive (n) & 1 & 1 & 2 & 0 & 1 & 2 & 0 & 0 & 3 & 1 \\
\hline & Range $\left(\mu \mathrm{g} \mathrm{kg}^{-1}\right)$ & 0.38 & 0.68 & $0.10-0.68$ & - & 8.77 & $0.32-1.02$ & - & - & $0.29-0.65$ & 0.22 \\
\hline \multirow[b]{2}{*}{ Milk and dairy products } & Samples (n) & 5 & 5 & 5 & 5 & 5 & 5 & 5 & 5 & 5 & 5 \\
\hline & Positive (n) & 0 & 3 & 0 & 0 & 0 & 1 & 0 & 0 & 1 & 0 \\
\hline \multirow{3}{*}{ Vegetables and vegetable products } & Samples (n) & 5 & 5 & 5 & 5 & 5 & 5 & 5 & 5 & 5 & 5 \\
\hline & Positive (n) & 2 & 3 & 2 & 0 & 1 & 2 & 0 & 0 & 3 & 2 \\
\hline & Range $\left(\mu \mathrm{g} \mathrm{kg}^{-1}\right)$ & $1.10-3.35$ & $0.19-0.71$ & $0.21-0.25$ & - & 1.22 & $1.85-3.29$ & - & - & $0.20-0.47$ & $0.22-0.26$ \\
\hline \multirow{3}{*}{ Fruits and fruit products } & Samples (n) & 5 & 5 & 5 & 5 & 5 & 5 & 5 & 5 & 5 & 5 \\
\hline & Positive (n) & 1 & 1 & 0 & 0 & 0 & 1 & 0 & 0 & 0 & 0 \\
\hline & Range $\left(\mu \mathrm{g} \mathrm{kg}^{-1}\right)$ & 0.2 & 6.62 & - & - & - & 0.21 & - & - & - & - \\
\hline \multirow{3}{*}{ Sugar and sugar products } & Samples (n) & 5 & 5 & 5 & 5 & 5 & 5 & 5 & 5 & 5 & 5 \\
\hline & Positive (n) & 1 & 0 & 0 & 0 & 0 & 0 & 0 & 0 & 0 & 0 \\
\hline & Range $\left(\mu \mathrm{g} \mathrm{kg}^{-1}\right)$ & 0.12 & - & - & - & - & - & - & - & - & - \\
\hline \multirow{3}{*}{ Beverages and water } & Samples (n) & 5 & 5 & 5 & 5 & 5 & 5 & 5 & 5 & 5 & 5 \\
\hline & Positive (n) & 1 & 0 & 0 & 0 & 0 & 0 & 0 & 0 & 0 & 0 \\
\hline & Range $\left(\mu \mathrm{g} \mathrm{kg}^{-1}\right)$ & 0.16 & - & - & - & - & - & - & - & - & - \\
\hline \multirow{3}{*}{ Alcohol beverages } & Samples (n) & 5 & 5 & 5 & 5 & 5 & 5 & 5 & 5 & 5 & 5 \\
\hline & Positive (n) & 2 & 4 & 3 & 0 & 0 & 1 & 0 & 0 & 0 & 0 \\
\hline & Range $\left(\mu \mathrm{g} \mathrm{kg}^{-1}\right)$ & $0.27-1.00$ & $2.26-17.62$ & $0.14-0.16$ & - & - & 0.12 & - & - & - & - \\
\hline
\end{tabular}




\section{Conclusions}

In this study, a sensitive and reliable UPLC-MS/MS method was developed to determine 10 emerging mycotoxins in 12 different food categories for the total diet study. The LODs and LOQs ranged from 0.0004 to $0.3 \mathrm{ng} \mathrm{mL}^{-1}$ and from 0.002 to $0.9 \mathrm{ng} \mathrm{mL}^{-1}$, respectively. ENNs exhibited the best sensitivity. Most mycotoxins showed satisfactory accuracy ranging between 70\% 130\% in 12 food matrices, with intra- and inter-precision within $12 \%$. After validation, the well-established method was successfully employed to study the occurrence of 10 mycotoxins in 60 food samples collected from five provinces within the $6^{\text {th }}$ China Total Diet Study, demonstrating its ultra-sensitivity and wide applicability. The preliminary results showed that except for $\mathrm{AOH}$, all of the mycotoxins were detected in $13.3 \% \sim 45 \%$ of the samples at ppt to low ppb levels mainly in eggs, cereals, legumes, potatoes, and the related products. These food categories need to be given more attention in the dietary exposure assessment of emerging mycotoxins.

\section{Materials and Methods}

\subsection{Materials and Reagents}

Certificated standard solutions of AOH, AME, TeA, BEA, TEN, ALT, and isotope labeled internal standards TEN- $\mathrm{d}_{3},{ }^{13} \mathrm{C}_{17}-\mathrm{TeA}$, and ${ }^{13} \mathrm{C}_{17}$-AFB2 were from Romer Labs (Tulln, Austria). ENNs (ENNA1, ENNA, ENNB1, and ENNB) were purchased from PriboLab (Biopolis, Singapore) and stored at $-40{ }^{\circ} \mathrm{C}$ in the dark. Acetonitrile and methanol were of LC-MS grade; formic acid, ammonium formate, aqueous solution of ammonium hydroxide ( $25 \%$ ), ammonium hydrogen carbonate, and ammonium dihydrogen phosphate were of HPLC grade (Fisher Scientific, Leicestershire, UK). The other chemicals or reagents were of analytical grade or better. A mixed standard solution consisting of $5 \mu \mathrm{g} / \mathrm{mL}$ of ATs and $0.5 \mu \mathrm{g} / \mathrm{mL}$ of ENNs and BEA, and a mixed internal standard solution containing $25 \mathrm{ng} / \mathrm{mL}$ of ${ }^{13} \mathrm{C}_{17}-\mathrm{AFB} 2,0.5 \mu \mathrm{g} / \mathrm{mL}$ of ${ }^{13} \mathrm{C}_{17}-\mathrm{TeA}$, and $0.5 \mu \mathrm{g} / \mathrm{mL}$ of $\mathrm{TEN}-\mathrm{d}_{3}$ were prepared in acetonitrile and stored at $-40{ }^{\circ} \mathrm{C}$ in the dark. These stock solutions were then diluted with the original mobile phase to obtain the appropriate working solutions and wait for the UPLC-MS/MS analysis. The solvent for the sample extraction was prepared by mixing $450 \mathrm{~mL}$ acetonitrile, $100 \mathrm{~mL}$ methanol, and $450 \mathrm{~mL}$ of $0.05 \mathrm{~mol} \mathrm{~L}^{-1}$ phosphate buffer (ammonium dihydrogen phosphate, $\mathrm{pH}$ 3.0). The Oasis HLB SPE columns (6 mL with $200 \mathrm{mg}$ stationary phase) were obtained from Waters (Milford, MA, USA).

\subsection{Food Consumption and Sampling}

Food consumption survey was conducted in 24 provinces (municipalities, autonomous region). Six survey sites (two urban sites and four rural sites) were required for provinces with a population of more than 50 million, while there were three survey sites (one urban site and two rural sites) in other provinces. At each site, 30 households were randomly selected to finish both a household survey by a weighing plus 3-day accounting method and an individual survey by a 3-day 24-hour dietary recall method. Food aggregation and consumption of each food item were obtained from the survey.

On this basis, food samples were collected from local food markets such as vegetable markets, grain shops, farmer's markets, or rural households in each sampling site, and then prepared according to the recipes following the local culinary habits. The composite of each food category was made by blending the prepared food with weights proportional to the average consumption in each province. These provincial composite samples were properly labeled and stored at $-20^{\circ} \mathrm{C}$ for analysis.

\subsection{Preparation of Standard Serials and Quality Control Samples}

The calibration standard solutions at levels of $0.05,0.1,0.2,0.5,1,2,5,10,20,50,100,200$, and $500 \mathrm{ng} / \mathrm{mL}$ for ATs and 0.005, 0.01, 0.02, 0.05, 0.1, 0.2, 0.5, 1, 2, 5, 10, 20, and $50 \mathrm{ng} / \mathrm{mL}$ for ENNs and BEA were made by serial dilutions of the mixed stock solution with acetonitrile/water (10/90,

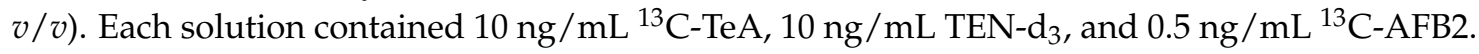


To ensure the accuracy of the analysis, three test samples from each batch of 20 samples were randomly selected and spiked with known amounts of the target analytes, serving as the quality control (QC) samples. The recoveries of the QC samples should be between $60-140 \%$ according to the EC guidelines [67].

\subsection{Sample Preparation}

After spiking with the isotope internal standards $\left({ }^{13} \mathrm{C}-\mathrm{TeA}, \mathrm{TEN}-\mathrm{d}_{3}\right.$ and $\left.{ }^{13} \mathrm{C}-\mathrm{AFB} 2\right), 2 \mathrm{~g}$ of food sample was incubated with $9 \mathrm{~mL}$ of extraction solution for $0.5 \mathrm{~h}$ at room temperature, ultrasonized for $0.5 \mathrm{~h}$, and centrifuged at $9000 \mathrm{rpm}$ for $10 \mathrm{~min}$. Exactly $5 \mathrm{~mL}$ of the supernatant was mixed with $15 \mathrm{~mL}$ $0.05 \mathrm{~mol} \mathrm{~L}^{-1}$ phosphate buffer (ammonium dihydrogen phosphate, $\mathrm{pH}$ 3.0). After vortex-mixing for $30 \mathrm{~s}$, the resulting mixture was loaded onto an Oasis HLB SPE column and allowed to pass through the sorbent slowly. The column was sequentially washed with $5 \mathrm{~mL}$ of methanol/water solution $(\mathrm{V} / \mathrm{V}=20 / 80)$ and eluted with $5 \mathrm{~mL}$ methanol and then $5 \mathrm{~mL}$ acetonitrile. A total of $10 \mathrm{~mL}$ of the eluent was nitrogen-dried at $40^{\circ} \mathrm{C}$, reconstituted in $1 \mathrm{~mL}$ acetonitrile/water $(\mathrm{V} / \mathrm{V}=10 / 90)$, vortexed for $30 \mathrm{~s}$, and centrifuged at 20,000 rpm for $30 \mathrm{~min}$ to collect the supernatant prior to LC-MS/MS analysis.

\subsection{LC-MS/MS Analysis}

Analysis was carried out on an Exion LC AD ${ }^{\mathrm{TM}}$ System (AB SCIEX, Concord, Ontario, Canada) coupled to a Triple Quad 6500+ mass spectrometer (AB SCIEX). The instrument operation was performed on Analyst ${ }^{\circledR}$ software and the data processing was analyzed on MultiQuant ${ }^{\mathrm{TM}}$ software. $^{-}$

\subsubsection{Chromatographic Condition}

Chromatographic separation of 10 emerging mycotoxins was performed on a UPLC column $\left(\right.$ CORTECS $^{\text {TM }}$ C18, $2.1 \times 100 \mathrm{~mm}, 1.6 \mu \mathrm{m}$ ) under a gradient elution. Acetonitrile (solvent A) combined with aqueous solution containing $5 \mathrm{mmol} \mathrm{L}^{-1}$ ammonia acetate and $0.01 \%$ ammonium hydroxide (solvent B) served as the mobile phase. After an initial time of $1 \mathrm{~min}$ at $8 \% \mathrm{~A}$, the proportion of A was increased linearly to $35 \%$ from $1-4 \mathrm{~min}$, and then increased to $74 \%$ within $2 \mathrm{~min}$, held at $74 \%$ for $1.5 \mathrm{~min}$, and then increased to $100 \%$ within $0.5 \mathrm{~min}$ and held for $3 \mathrm{~min}$, finally reduced to $8 \%$ within $0.1 \mathrm{~min}$ and held for $4 \mathrm{~min}$, with the total runtime of $15 \mathrm{~min}$. The flow rate was set at $0.4 \mathrm{~mL} / \mathrm{min}$. The column was maintained at a constant temperature of $50{ }^{\circ} \mathrm{C}$ while the temperature of the autosampler was kept at $10^{\circ} \mathrm{C}$.

\subsubsection{Mass Spectrometry Condition}

The detection and analysis were performed on a Triple Quad 6500+ mass spectrometer, equipped with an ESI source. The instrument parameters in MRM mode in both positive and negative ionization were optimized for each analyte by scanning two fragmentation pathways with the parameters including cone voltage (CV) and collision energies (CE) given in Table 1. Other settings were as follows: curtain gas, $20 \mathrm{psi}$; source temperature, $450{ }^{\circ} \mathrm{C}$; ion spray voltage, $-4500 \mathrm{~V}$ and $+5500 \mathrm{~V}$, respectively; ion source gas 1 (sheath gas) $60 \mathrm{psi}$; ion source gas 2 (drying gas) 55 psi; collision gas (nitrogen) medium.

\subsection{Method Validation}

Validation of the method was evaluated referring to the guidelines defined by the European Communities (EC) [57] and European Medicines Agency (EMEA) [58] concerning linearity, accuracy, precision, and sensitivity. Accuracy was investigated from the method recovery $\left(R_{M}\right)$ at three spiking levels in 12 types of food matrices with internal standard correction.

Supplementary Materials: The following are available online at http:/ /www.mdpi.com/2072-6651/11/3/166/s1, Table S1: Sensitivity, extraction recovery, and matrix effect of the method for each food category. Table S2: Accuracy and precision of the method for each food category. 
Author Contributions: Methodology, D.S., N.Q., and S.Z.; Validation, D.S. and N.Q.; Formal Analysis, D.S.; Investigation, B.L. and S.Z.; Writing-Original Draft Preparation, D.S. and S.Z.; Writing-Review and Editing, S.Z.; Supervision, Y.Z.; Project Administration, J.L. and Y.W.; Funding Acquisition, S.Z. and Y.W.

Funding: This research was funded by the National Natural Science Foundation of China (31871723), National Key Research and Development Program of China (2017YFC1600500), and CFSA "523" High Level Talents Development Project.

Conflicts of Interest: The authors declare no conflict of interest.

\section{References}

1. Chełkowski, J.; Visconti, A. Alternaria: Biology, Plant Diseases and Metabolites; Elsevier: Amsterdam, The Netherlands, 1992.

2. Scott, P.M.; Kanhere, S.R. Chromatographic method for Alternaria toxins in apple juice. Methods Mol. Biol. 2001, 157, 225-234. [PubMed]

3. Carson, M.L. Epidemiology and yield losses associated with Alternaria blight of sunflower. Phytopathology 1985, 75, 1151-1156. [CrossRef]

4. De Berardis, S.; De Paola, E.L.; Montevecchi, G.; Garbini, D.; Masino, F.; Antonelli, A.; Melucci, D. Determination of four Alternaria alternata mycotoxins by QuEChERs approach coupled with liquid chromatography-tandem mass spectrometry in tomato-based and fruit-based products. Food Res. Int. 2018, 106, 677-685. [CrossRef] [PubMed]

5. Rang, J.; Crous, P.W.; Mchau, G.R.A.; Serdani, M.; Song, S. Phylogenetic analysis of Alternaria spp. associated with apple core rot and citrus black rot in South Africa. Mycol. Res. 2002, 106, 1151-1162. [CrossRef]

6. Kosiak, B.; Torp, M.; Skjerve, E.; Andersen, B. Alternaria and Fusarium in Norwegian grains of reduced quality-a matched pair sample study. Int. J. Food Microbiol. 2004, 93, 51-62. [CrossRef]

7. Asam, S.; Konitzer, K.; Schieberle, P.; Rychlik, M. Stable isotope dilution assays of alternariol and alternariol monomethyl ether in beverages. J. Agric. Food Chem. 2009, 57, 5152-5160. [CrossRef]

8. Solfrizzo, M.; De Girolamo, A.; Vitti, C.; Visconti, A. Liquid chromatographic determination of Alternaria toxins in carrots. J. AOAC Int. 2004, 87, 101-106. [PubMed]

9. Siegel, D.; Feist, M.; Proske, M.T.; Koch, M.; Nehls, I. Quantification of the Alternaria mycotoxin tenuazonic acid in beer. Food Chem. 2010, 120, 902-906. [CrossRef]

10. Ostry, V. Alternaria Mycotoxins: An overview of chemical characterization, producers, toxicity, analysis and occurrence in foodstuffs. World Mycotoxin J. 2008, 1, 175-188. [CrossRef]

11. Gruber-Dorninger, C.; Novak, B.; Nagl, V.; Berthiller, F. Emerging Mycotoxins: Beyond Traditionally Determined Food Contaminants. J. Agric. Food Chem. 2017, 65, 7052-7070. [CrossRef] [PubMed]

12. Pero, R.W.; Posner, H.; Blois, M.; Harvan, D.; Spalding, J.W. Toxicity of metabolites produced by the Alternaria. Environ. Health Perspect. 1973, 4, 87-94. [CrossRef] [PubMed]

13. Pfeiffer, E.; Eschbach, S.; Metzler, M. Alternaria toxins: DNA strand-breaking activity in mammalian cells in vitro. Mycotoxin Res. 2007, 3, 152-157. [CrossRef] [PubMed]

14. Brugger, E.M.; Wagner, J.; Schumacher, D.M.; Koch, K.; Podlech, J.; Metzler, M.; Lehmann, L. Mutagenicity of the mycotoxin alternariol in cultured mammalian cells. Toxicol. Lett. 2006, 3, 221-230. [CrossRef]

15. Liu, G.T.; Qian, Y.Z.; Zhang, P.; Dong, W.H.; Qi, Y.M.; Guo, H.T. Etiological role of Alternaria alternata in human esophageal cancer. Chin. Med. J. 1992, 105, 394-400.

16. EFSA. Scientific opinion on the risks for animal and public health related to the presence of Alternaria toxins in feed and food. EFSA J. 2011, 9, 2407. [CrossRef]

17. EFSA. Dietary exposure assessment to Alternaria toxins in the European population. EFSA J. 2016, 14, 4654. [CrossRef]

18. Gaumann, E.; Roth, S.M.; Ettlinger, L.; Plattner, P.A.; Nager, U. Enniatin, ein neues gegen Mykobakterien wirksames Antibiotikum. Experimentia 1947, 3, 202-203. [CrossRef]

19. Bernardini, M.; Carillia, A.; Pacioni, G.; Santurbano, B. Isolation of beauvericin from Paecilomyces fumoso-roseus. Phytochemistry 1975, 14, 1865. [CrossRef]

20. Deol, B.S.; Ridley, D.D.; Singh, P. Isolation of cyclodepsipeptides from plant pathogenic fungi. Aust. J. Chem. 1978, 31, 1397-1399. [CrossRef] 
21. Nilanonta, C.; Isaka, M.; Chanphen, R.; Thong, O.N.; Tanticharoen, M.; Thebtaranonth, Y. Unusual enniatins produced by the insect pathogenic fungus Verticillium hemipterigenum: Isolation and studies on precursor-directed biosynthesis. Tetrahedron 2003, 59, 1015-1020. [CrossRef]

22. Santini, A.; Meca, G.; Uhlig, S.; Ritieni, A. Fusaproliferin, beauvericin and enniatins: Occurrence in food-a review. World Mycotoxin J. 2012, 5, 71-81. [CrossRef]

23. Zinedine, A.; Meca, G.; Manes, J.; Font, G. Further data on the occurrence of Fusarium emerging mycotoxins enniatins (A, A1, B, B1), fusaproliferin and beauvericin in raw cereals commercialized in Morocco. Food Control 2011, 22, 1-5. [CrossRef]

24. Kouri, K.; Lemmens, M.; Lemmens, G.R. Beauvericin-induced channels in ventricular myocytes and liposomes. Biochim. Biophys. Acta 2003, 1609, 203-210. [CrossRef]

25. Kamyar, M.; Rawnduzi, P.; Studenik, C.R. Investigation of the electrophysiological properties of enniatins. Arch. Biochem. Biophys. 2004, 429, 215-223. [CrossRef]

26. Ojcius, D.M.; Zychlinsky, A.; Zheng, L.M.; Young, J.D. Ionophore-induced apoptosis: Role of DNA fragmentation and calcium fluxes. Exp. Cell Res. 1991, 197, 43-49. [CrossRef]

27. Fornelli, F.; Minervini, F.; Logrieco, A. Cytotoxicity of fungal metabolites to lepidopteran (Spodoptera frugiperda) cell line (SF-9). J. Invertebr. Pathol. 2004, 85, 74-79. [CrossRef] [PubMed]

28. Logrieco, A.; Moretti, A.; Fornelli, F.; Fogliano, V.; Ritieni, A.; Caiaffa, M.F. Fusaproliferin production by Fusarium subglutinans and its toxicity to Artemia salina SF-9 insect cells and IARC/LCL171 human B lymphocytes. Appl. Environ. Microbiol. 1996, 62, 3378-3384.

29. Josephs, R.D.; Krska, R.; Schuhmacher, R.; Grasserbauer, M.A. Rapid method for the determination of the Fusarium mycotoxin beauvericin in maize. Fresenius J. Anal. Chem. 1999, 363, 130-131. [CrossRef]

30. Logrieco, A.; Rizzo, A.; Ferracane, R.; Ritieni, A. Occurrence of beauvericin and enniatins in wheat affected by Fusarium avenaceum head blight. Appl. Environ. Microbiol. 2002, 68, 82-85. [CrossRef]

31. Krska, R.; Schuhmache, R.; Grasserbauer, M. Determination of the Fusarium mycotoxin beauvericin at micrograms $/ \mathrm{kg}$ levels in corn by high-performance liquid chromatography with diode-array detection. J. Chromatogr. A 1996, 746, 233-238. [CrossRef]

32. Hasan, H.A. Alternaria mycotoxins in black rot lesion of tomato fruit: Conditions and regulation of their production. Mycopathologia 1995, 130, 171-177. [CrossRef]

33. Pavón, M.Á.; Luna, A.; de la Cruz, S.; González, I.; Martín, R.; García, T. PCR-based assay for the detection of Alternaria species and correlation with HPLC determination of altenuene, alternariol and alternariol monomethyl ether production in tomato products. Food Control 2012, 25, 45-52. [CrossRef]

34. Sørensen, J.L.; Nielsen, K.F.; Rasmussen, P.H. Development of a LC-MS/MS Method for the Analysis of Enniatins and Beauvericin in Whole Fresh and Ensiled Maize. J. Agric. Food Chem. 2008, 56, 10439-10443. [CrossRef] [PubMed]

35. Jestoi, M.; Rokka, M.; Eila, J. Determination of Fusarium mycotoxins beauvericin and enniatins (A, A1, B, B1) in eggs of laying hens using liquid chromatography-tandem mass spectrometry (LC-MS/MS). Food Chem. 2009, 115, 1120-1127. [CrossRef]

36. Prelle, A.; Spadaro, D.; Garibaldi, A.; Gullino, M.L. A new method for detection of five alternaria toxins in food matrices based on LC-APCI-MS. Food Chem. 2013, 140, 161-167. [CrossRef] [PubMed]

37. Yoshinari, T.; Suzuki, Y.; Sugitakonishi, Y. Occurrence of beauvericin and enniatins in wheat flour and corn grits on the Japanese market and their co-contamination with type $\mathrm{B}$ trichothecene mycotoxins. Food Addit. Contam. A 2016, 33, 1620-1626. [CrossRef] [PubMed]

38. Asam, S.; Konitzer, K.; Rychlik, M. Precise determination of the Alternaria mycotoxins alternariol and alternariol monomethyl ether in cereal, fruit and vegetable products using stable isotope dilution assays. Mycotoxin Res. 2011, 27, 23-28. [CrossRef]

39. Noser, J.; Schneider, P.; Rother, M.; Schmutz, H. Determination of six Alternaria toxins with UPLC-MS/MS and their occurrence in tomatoes and tomato products from the Swiss market. Mycotoxin Res. 2011, 27, 265-271. [CrossRef]

40. Walravens, J.; Mikula, H.; Rychlik, M.; Asam, S.; Devos, T.; Njumbe, E.E. Validated UPLC-MS/MS methods to quantitate free and conjugated Alternaria toxins in commercially available tomato products and fruit and vegetable juices in Belgium. J. Agric. Food Chem. 2016, 64, 5101-5109. [CrossRef] 
41. Walravens, J.; Mikula, H.; Rychlik, M.; Asam, S.; Ediage, E.N.; Di Mavungu, J.D. Development and validation of an ultrahigh-performance liquid chromatography tandem mass spectrometric method for the simultaneous determination of free and conjugated Alternaria toxins in cereal-based foodstuffs. J. Chromatogr. A 2014, 1372, 91-101. [CrossRef] [PubMed]

42. Puntscher, H.; Kütt, M.L.; Skrinjar, P.; Mikula, H.; Podlech, J.; Fröhlich, J.; Marko, D.; Warth, B. Tracking emerging mycotoxins in food: Development of an LC-MS/MS method for free and modified alternaria toxins. Anal. Bioanal. Chem. 2018, 410, 4481-4494. [CrossRef] [PubMed]

43. Sophie, F.; Siska, C.; Mathias, D.; Gunther, A. Emerging fusarium and alternaria mycotoxins: Occurrence, toxicity and toxicokinetics. Toxins 2017, 9, 228.

44. WHO. Total Diet Studies: A Recipe for Safer Food. 2005. Available online: http://www.who.int/foodsafety/ chem/TDS_recipe_2005_en.pdf (accessed on 17 March 2019).

45. Sirot, V.; Fremy, J.M.; Leblanc, J.C. Dietary exposure to mycotoxins and health risk assessment in the second French total diet study. Food Chem. Toxicol. 2013, 52, 1-11. [CrossRef] [PubMed]

46. Eduardo, B.; María, I.; Tania, P.; Cristina, R.; Félix, H. Development of sensitive and rapid analytical methodology for food analysis of 18 mycotoxins included in a total diet study. Anal. Chim. Acta 2013, 783C, $39-48$.

47. Raad, F.; Nasreddine, L.; Hilan, C.; Bartosik, M.; Parent-Massin, D. Dietary exposure to aflatoxins, ochratoxin a and deoxynivalenol from a total diet study in an adult urban lebanese population. Food Chem. Toxicol. 2014, 73, 35-43. [CrossRef]

48. Sprong, R.C.; De, W.L.; Te, B.J.D.; Alewijn, M.; Lopez, P.; Mengelers, M.J.B. A mycotoxin-dedicated total diet study in the netherlands in 2013: Part iii-Exposure and risk assessment. World Mycotoxin J. 2016, 9, 109-128. [CrossRef]

49. Wu, Y.N.; Li, X.W. The Fourth China Total Diet Study; Chemical Industry Press: Beijing, China, 2015.

50. Wu, Y.N.; Zhao, Y.F.; Li, J.G. The Fifth China Total Diet Study; Science Press: Beijing, China, 2018.

51. Jesus, B.; Juan-Carlos, M.; Samira, E.A.; Jordi, M.; Andellah, Z. Simultaneous determination of Fusarium mycotoxins in wheat grain from Morocco by liquid chromatography coupled to triple quadrupole mass spectrometry. Food Control 2014, 46, 1-5.

52. Sebastià, N.; Meca, G.; Soriano, J.M.; Mañes, J. Presence of Fusarium emerging mycotoxins in tiger-nuts commercialized in Spain. Food Control 2012, 25, 631-635. [CrossRef]

53. Josefa, T.; Guillermina, F.; Jorge, M.; Emilia, F. Nuts and dried fruits: Natural occurrence of emerging Fusarium mycotoxins. Food Control 2013, 33, 215-220.

54. Katharina, H.; Marina, G.; Jan, S.; Michael, R. Multi-mycotoxin stable isotope dilution LC-MS/MS method for Fusarium toxins in beer. Food Chem. 2017, 218, 447-454.

55. Antonia, G.F.; Roberto, R.; María, L.G.; José, L.M.V. Multi-mycotoxin analysis in eggs using a QuEChERS-based extraction procedure and ultra-high-pressure liquid chromatography coupled to triple quadrupole mass spectrometry. J. Chromatogr. A 2011, 1218, 4349-4356.

56. Souheib, O.; Guiseppe, M.; Ahmed, M.; Abdelwahed, G.; Jordi, M. Determination of Fusarium mycotoxins enniatins, beauvericin and fusaproliferin in cereals and derived products from Tunisia. Food Control 2011, 22, 1373-1377.

57. Commission Decision 2002/657/EC Implementing Council Directive 96/23/EC Concerning the Performance of Analytical Methods and the Interpretation of Results. Available online: https://eur-lex.europa.eu/ LexUriServ/LexUriServ.do?uri=OJ:L:2002:221:0008:0036:EN:PDF (accessed on 17 March 2019).

58. European Medicines Agency. Guideline on Bioanalytical Method Validation. Available online: http:/ / www. ema.europa.eu/docs/en_GB/document_library/Scientific_guideline/2011/08/WC500109686.pdf (accessed on 12 January 2016).

59. Kataoka, H.; Itano, M.; Ishizaki, A. Determination of patulin in fruit juice and dried fruit samples by in-tube solid-phase microextraction coupled with liquid chromatography-mass spectrometry. J. Chromatogr. A 2009, 1216, 3746-3750. [CrossRef] [PubMed]

60. Fente, C.A.; Jaimez, J.; Vazquez, B.I. Determination of alternariol in tomato paste using solid phase extraction and high-performance liquid chromatography with fluorescence detection. Analyst 1998, 123, 2277-2280. [CrossRef] 
61. Rodrigo, E.M.; Gezimar, D.; Edson, R. Analysis of Alternariol and Alternariol Monomethyl Ether on Flavedo and Albedo Tissues of Tangerines (Citrus reticulata) with Symptoms of Altemaria Brown Spot. J. Agric. Food Chem. 2007, 55, 4980-4986.

62. Herebian, D.; Zühlke, S.; Lamshöft, M.; Spiteller, M. Multi-Mycotoxin Analysis in Complex Biological Matrices Using LC-ESI/MS: Experimental Study Using Triple Stage Quadrupole and LTQ-Orbitrap. J. Sep. Sci. 2009, 32, 939-948. [CrossRef] [PubMed]

63. Nazari, F.; Sulyok, M.; Kobarfard, F.; Yazdanpanah, H.; Krska, R. Evaluation of Emerging Fusarium mycotoxins beauvericin, Enniatin, Fusaproliferin and Moniliformin in Domestic Rice in Iran. Iran. J. Pharm. Res. 2015, 14, 505-512.

64. Michael, S.; Rudolf, K.; Rainer, S. Application of an LC-MS/MS based multi-mycotoxin method for the semi-quantitative determination of mycotoxins occurring in different types of food infected by moulds. Food Chem. 2010, 119, 408-416.

65. Hamler, K.; Rychlik, M. Multi-mycotoxin stable isotope dilution LC-MS/MS method for Fusarium toxins in cereals. Anal. Bioanal. Chem. 2016, 218, 447-454.

66. Matuszewski, B.K.; Constanzer, M.L.; Chavez-Eng, C.M. Strategies for the assessment of matrix effect in quantitative bioanalytical methods based on HPLC-MS/MS. Anal. Chem. 2003, 75, 3019-3030. [CrossRef]

67. European Commission. Method Validation and Quality Control Procedures for Pesticide Residues Analysis in Food and Feed. Document No. SANTE/11813/2017. 2017. Available online: https:/ / ec.europa.eu/food/sites/ food/files/plant/docs/pesticides_mrl_guidelines_wrkdoc_2017-11813.pdf (accessed on 1 January 2018).

(C) 2019 by the authors. Licensee MDPI, Basel, Switzerland. This article is an open access article distributed under the terms and conditions of the Creative Commons Attribution (CC BY) license (http:/ / creativecommons.org/licenses/by/4.0/). 